\title{
An MRI-Based Semiquantitative Index for the Evaluation of Brain Atrophy and Lesions in Alzheimer's Disease, Mild Cognitive Impairment and Normal Aging
}

\author{
Wei Chen ${ }^{a, g} \quad$ Xiaowei Song $^{\text {a,b }} \quad$ Yunting Zhang ${ }^{g}$ Sultan Darvesh ${ }^{\text {c, e }}$ \\ Ningnannan Zhang ${ }^{a, g}$ Ryan C.N. D'Arcy ${ }^{a, d}$ Sandra Black ${ }^{f}$ \\ Kenneth Rockwood ${ }^{b, e}$ \\ ${ }^{a}$ National Research Council Canada, Institute for Biodiagnostics (Atlantic), b Division of Geriatric Medicine, \\ Department of Medicine, 'Departments of Medicine (Neurology) and Anatomy and Neurobiology, and \\ ${ }^{\mathrm{d}}$ Departments of Radiology and Psychology and Neuroscience, Dalhousie University, and ${ }^{\mathrm{e}}$ Centre for Health Care \\ of the Elderly, QEII Health Sciences Centre, Halifax, N.S., and ${ }^{\mathrm{f} D e p a r t m e n t ~ o f ~ M e d i c i n e ~(N e u r o l o g y) ~ a n d ~ H e a r t ~}$ \\ and Stroke Foundation Centre for Stroke Recovery, Sunnybrook Health Sciences Centre, University of Toronto, \\ Toronto, Ont., Canada; ${ }^{9}$ Department of Radiology of the General Hospital, Tianjin Medical University, Tianjin, China
}

\section{Key Words}

Aging $\cdot$ Alzheimer's disease $\cdot$ Brain lesions • Brain atrophy • Mild cognitive impairment

\begin{abstract}
Background: This study investigates how $\mathrm{T}_{1}$-weighted MRI can be used to evaluate brain anatomical changes. We investigated these changes in Alzheimer's disease (AD) and normal aging. Methods: A semiquantitative brain atrophy and lesion index (BALI) was constructed by adapting existing visual rating scales and validated in 3 datasets. Results: The $\mathrm{T}_{1}$ - and $\mathrm{T}_{2}$-weighted-imaging-based scores were highly correlated. They were both closely associated with age and with cognitive test scores. Conclusion: The $\mathrm{T}_{1}$-based BALI helps describe brain structural variability in $A D$, mild cognitive impairment and normal aging.

Copyright $\odot 2010$ S. Karger AG, Basel
\end{abstract}

\section{Introduction}

Brain anatomical changes are common in older adults. The most common forms of adverse brain anatomical changes are focal and diffuse atrophy, white matter lesions, cortical and subcortical infarcts, and microinfarcts [1-4]. Of these, white matter lesions are more frequently reported in patients with Alzheimer's disease (AD) and mild cognitive impairment (MCI). Even so, pathological changes are very widespread and their possible significance needs to be considered. For example, in a large

Data used in the preparation of this article were partly obtained from the Alzheimer's Disease Neuroimaging Initiative (ADNI) database (www.loni.ucla.edu/ADNI). As such, the investigators within the ADNI contributed to the design and implementation of ADNI and/ or provided data but did not participate in the analysis or writing of this report. The principal investigator of the initiative is Dr. Michael W. Weiner. A complete list of the ADNI investigators can be found at the following website: www.loni.ucla.edu/ADNI/Collaboration/ ADNI_Manuscript_Citations.pdf.

\section{KARGER}

두 2010 S. Karger AG, Basel

Fax +41613061234 E-Mail karger@karger.ch www.karger.com
Xiaowei Song, PhD, MSCS; Kenneth Rockwood, MD, FRCPC Neuroimaging Research Laboratory, National Research Council Canada Institute for Biodiagnostics (Atlantic)

Suite 3900, 1796 Summer Street, Halifax, NS B3H 3A7 (Canada)

E-Mail Xiaowei.Song@nrc.ca; Kenneth.Rockwood@dal.ca 
Table 1. Baseline demographics of the study sample

\begin{tabular}{|c|c|c|c|c|c|c|}
\hline & \multicolumn{6}{|l|}{ Dataset } \\
\hline & \multicolumn{3}{|l|}{1} & \multicolumn{2}{|l|}{2} & \multirow{2}{*}{$\frac{3}{\mathrm{HC}}$} \\
\hline & $\mathrm{AD}$ & MCI & $\mathrm{HC}$ & $\mathrm{AD}$ & $\mathrm{HC}$ & \\
\hline Number & 35 & 68 & 50 & 14 & 30 & 96 \\
\hline Age, years & $75.1 \pm 8.9$ & $75.2 \pm 7.5$ & $75.8 \pm 7.5$ & $76.4 \pm 10.0$ & $73.7 \pm 6.1$ & $72.9 \pm 7.4$ \\
\hline Female, \% & 62.9 & 35.3 & 66.0 & 42.9 & 63.3 & 50.0 \\
\hline $\begin{array}{l}\text { MMSE (of 30) } \\
\text { or } 3 \text { MS (of 100) score }\end{array}$ & $\begin{array}{l}22.1 \pm 3.6 \\
\text { of } 30\end{array}$ & $\begin{array}{l}25.7 \pm 3.0 \\
\text { of } 30\end{array}$ & $\begin{array}{l}28.8 \pm 1.2 \\
\text { of } 30\end{array}$ & $\begin{array}{l}76.5 \pm 7.4 \\
\text { of } 100\end{array}$ & $\begin{array}{l}96.7 \pm 4.3 \\
\text { of } 100\end{array}$ & $\begin{array}{l}26.4 \pm 4.1^{*} \\
\text { of } 30\end{array}$ \\
\hline
\end{tabular}

Age values are means $\pm \mathrm{SD} . \mathrm{HC}=$ Healthy controls; $\mathrm{MMSE}=$ Mini-Mental State Examination; $3 \mathrm{MS}=$ Modified Mini-Mental Scale. ${ }^{*}$ For randomly selected third of the study sample.

community-based study, about $6 \%$ of people aged $45-59$ years showed no white matter lesions; this decreased to $2 \%$ of people aged 75 years and older [5].

To evaluate brain lesions, several MRI visual rating scales have been used [6-10]. The rating scales vary by locations under study, by the grading system used, by the size of validation samples, and by imaging modality. Most visual rating scales focus on discrete lesions in localized structures and require proton density imaging, $\mathrm{T}_{2}$-weighted imaging (T2WI) or fluid-attenuated inversion recovery imaging [11]. Although brain lesion rating scales go back to the days of $\mathrm{CT}$, rating scales for highfield MRI (i.e. 3-tesla or higher), which are increasingly being used for functional MRI (fMRI), have yet to be developed.

Brain lesions have been linked with cognitive deficits in both normal aging and AD dementia [12-16]. Such anatomical changes make reliable inference of brain function difficult. In most fMRI experiments, high-resolution $\mathrm{T}_{1}$-weighted imaging (T1WI) is used for anatomical images, thus it would be helpful to understand to what extent high-resolution T1WI may be used to investigate brain anatomical changes and their effects on cognition. Using a rating scale to assess structural changes on T1WI and summarize multiple deficits could provide a standard way to describe brain anatomy for functional neuroimaging. Although neuroanatomical abnormalities might be heterogeneous, each can affect brain function, such that their combined effects might be significant.

The purpose of this paper is to investigate the relationship between T1WI- and T2WI-based evaluations of brain structural changes in healthy older adults and people with AD and MCI. In particular, we examined whether T1WI can be used to describe whole brain changes as well as the relationship between brain anatomical changes and cognition. For these purposes, a semiquantitative brain atrophy and lesion index (BALI) was developed, by adapting existing visual rating scales. The T1WI-based BALI score was compared with the T2WI-based score to assess reliability and for content, construct and predictive validation. To evaluate the general utility of the BALI, three independent structural MRI datasets were used.

\section{Materials and Methods}

\section{Data}

Data were obtained from the Alzheimer's Disease Neuroimaging Initiative (ADNI; dataset 1) and from 4-tesla (dataset 2) and 3-tesla (dataset 3) MRI studies. Each study received local research ethics board approval and informed consent was obtained from each participant.

Dataset 1. The ADNI was launched in 2003 as a multiyear, public-private partnership to combine neuroimaging with other biological markers and with neuropsychological and clinical assessments to measure the progression of MCI and early AD [17]. ADNI data were downloaded with permission. The analysis was based on $35 \mathrm{AD}$ patients, $68 \mathrm{MCI}$ patients and 50 healthy controls (table 1). All had T1WI (3-D magnetization-prepared rapid gradient echo sequence; $1.2 \mathrm{~mm}$ thickness) and T2WI (2-D axial, fast spin echo; $3 \mathrm{~mm}$ thickness) at 3-tesla [18], as well as cognitive tests (e.g. MMSE, Mini-Mental State Examination).

Dataset 2. Forty-four subjects (14 early AD, 30 age-matched healthy controls) were recruited from 2006 to 2010. The T1WI data were acquired at 4-tesla (Varian-Oxford; $35 \mathrm{mT} / \mathrm{m}$ gradient) using a 3-D magnetization-prepared fast low-angle shot sequence $(\mathrm{TR} / \mathrm{TE}=10.1 / 5 \mathrm{~ms}$; slice thickness $=1.2 \mathrm{~mm})$. Cognitive status of the subjects was assessed using the Modified Mini-Mental Scale (table 1).

Dataset 3. Ninety-six healthy older adults were recruited in 2009. The 3-tesla device used a spin echo sequence for T1WI (TR/ $\mathrm{TE}=1,776 / 25.9 \mathrm{~ms})$ and fast spin echo for T2WI $(\mathrm{TR} / \mathrm{TE}=$ $4,300 / 123 \mathrm{~ms}$ ). The slice thickness was $6 \mathrm{~mm}$ for both scans. An 
Table 2. Categorizing and grading criteria of the BALI

\begin{tabular}{|c|c|}
\hline Categories & Criteria \\
\hline $\begin{array}{l}\text { GM-SV (gray } \\
\text { matter lesions } \\
\text { and small vessels) }\end{array}$ & $\begin{array}{l}0=\text { absence; } 1 \text { = punctuate foci in gray matter or multiple small vessels in subcortical area; } \\
2=\text { beginning confluence of foci in gray matter or diffuse small vessels in subcortical area; } \\
3=\text { large confluent lesions in gray matter (rare, evidence for stroke-related malacia foci) }\end{array}$ \\
\hline $\begin{array}{l}\mathrm{PV} \text { (periven- } \\
\text { tricular lesions) }\end{array}$ & $\begin{array}{l}0=\text { absence; } 1=\text { 'caps' or pencil-thin lining; } 2=\text { smooth 'halo'; } 3=\text { irregular periventricular } \\
\text { abnormal signal intensities extending into the deep white matter }\end{array}$ \\
\hline $\begin{array}{l}\text { DWM (deep } \\
\text { white matter } \\
\text { lesions) }\end{array}$ & $\begin{array}{l}0=\text { absence; } 1=\text { punctuate foci; } 2=\text { beginning of confluence foci; } 3=\text { large confluent areas; } \\
4=\text { large confluent white matter areas involving all cerebral lobes; } 5=\text { complete confluent } \\
\text { white matter disease }\end{array}$ \\
\hline $\begin{array}{l}\text { BG (basal ganglia } \\
\text { and surrounding } \\
\text { area lesions) }\end{array}$ & $0=$ absence; $1=1$ focal lesion; $2=>1$ focal lesion; $3=$ large confluent lesions \\
\hline $\begin{array}{l}\text { IT (infratentorial } \\
\text { region lesions) }\end{array}$ & $0=$ absence; $1=1$ focal lesion; $2=>1$ focal lesion; $3=$ large confluent lesions \\
\hline $\begin{array}{l}\text { GA (global } \\
\text { atrophy) }\end{array}$ & $0=$ no obvious atrophy; $1=$ mild atrophy $2=$ moderate atrophy; $3=$ severe atrophy \\
\hline Other lesions & $\begin{array}{l}0=\text { no other kind of disease; } 1=\text { any } 1 \text { kind of brain neoplasm, deformation or trauma; } \\
2=\text { any } 2 \text { kinds of brain neoplasm, deformation or trauma; } 3=\text { simultaneous presence } \\
\text { of brain neoplasm, deformation and trauma }\end{array}$ \\
\hline
\end{tabular}

MMSE score was available for a randomly selected third of the sample (table 1).

\section{Construction of the BALI}

Seven categories were included in the BALI, which covered various common types of changes observed in the aging brain, in both supratentorial and infratentorial regions (table 2). The supratentorial lesions included gray matter lesions in the cerebral cortices and small vessels (that can be readily seen using 3-tesla and higher-field MRI) in the adjacent subcortical regions (GM$\mathrm{SV}$ ), white matter lesions that included periventricular lesions (PV) and deep white matter lesions (DWM) and basal ganglia lesions (BG; consisting of the caudate, putamen, globus pallidus nuclei, thalamus and internal capsule). The infratentorial lesions (IT) category assessed damage to the cerebellum and the brain stem. Global atrophy (GA) was designated as a component of the BALI to assess the shrinkage of the whole brain and the enlargement of the ventricles and subarachnoid spaces. An 'other lesions' category was included to cover neoplasm, trauma and deformation, among others.

A value between 0 and 3 was assigned to each category based on severity, with higher score meaning greater severity. Alerted to possible ceiling effects within the DWM category, where initially about a quarter of subjects had maximum scores (i.e. DWM subscore $=3$ ), we added 2 grades ( 4 and 5) to the DWM category (table 2). The images were assessed independently by 2 radiologists trained to use this method and blind to the demographic and cognitive status of the participants. To minimize recall bias, the T1WI and T2WI images were assessed separately on different days for randomly selected samples. Important lesions within a given category were defined as a subscore of $\geq 2$. Figure 1 shows representative images demonstrating lesions of various subcategories and the corresponding lesion scores.

\section{Statistical Analyses}

The interrater agreement rate was evaluated using the interclass correlation coefficient (ICC) on a random sample of $25 \%$ of the subjects in each dataset, with raters as independent variables [19]. Group mean differences between T1WI- and T2WI-based BALI total scores and subscores were examined using the pairwise $t$ test. Comparisons of means between diagnoses and between imaging types used analysis of variance (ANOVA) and two-way ANOVA. Tukey's multiple comparison tests were performed accordingly. Interrelations between variables were examined using correlation and regression analyses. Sensitivity and specificity analyses were performed and receiver operating characteristic (ROC) curves were used to evaluate BALI scores in identifying individuals with AD. Data were analyzed using SPSS 15.0 software and codes developed in Matlab version 2007. The level of significance was set at $\mathrm{p}<0.05$ (two-tailed)

\section{Results}

The interrater agreement analysis showed high reliability (ICC $=0.89,95 \%$ CI $0.81-0.93$ for the T1WI-based score; ICC $=0.86,95 \%$ CI $0.74-0.92$ for the T2WI-based score). 

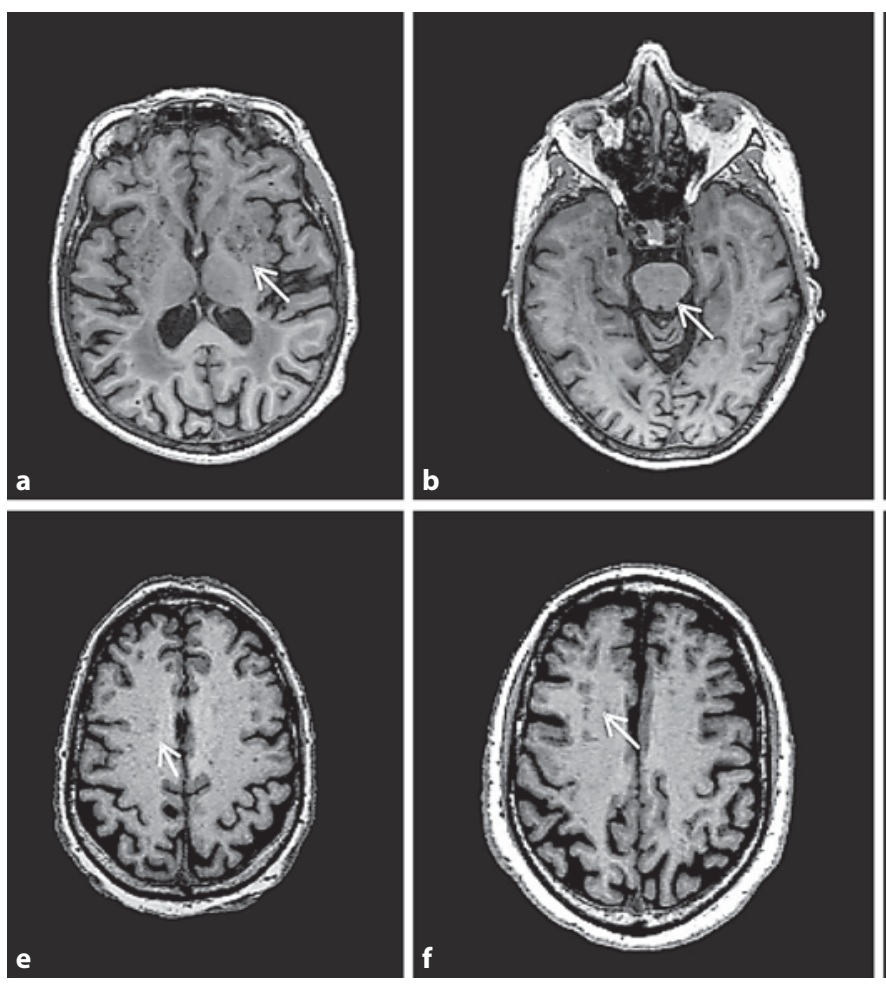

Fig. 1. Representative images and the corresponding lesion scores on T1WI of different subjects. a-d Lesions in subcategories of BG (a), IT (b), PV (c) and GM-SV (d). Confluent hypointensities (arrows) are seen in the bilateral basal ganglia areas $(\mathbf{a} ; \mathrm{BG}=3)$, pons

Brain lesions were common in each dataset (table 3). Most subjects had a moderate BALI score, and none was free of lesions (datasets 1-3: minimum $=5,6,3$; maximum $=16,16,17$; median and mean $=10,10,9)$. Brain lesions were seldom restricted to a single category. Across datasets, nearly $85 \%$ of the participants showed various grades of lesions involving multiple categories (i.e. BG, DWM, PV, IT and GM-SV). Except for the 'other lesion' category, important lesions (i.e. subscore in a category of $\geq 2$ ) were observed for each category. The highest subscore was in the DWM category, with $20 \%$ of the subjects having a DWM subscore of 3 and $9 \%$ of 4 , but none of 5 . Higher BALI total scores were revealed by T2WI than by T1WI for the datasets (two-way ANOVA: $\mathrm{n}=249, \mathrm{~F}=$ 7.65, $\mathrm{p}=0.009$ ) (table 3), which was most obvious in PV and DWM. Regardless of imaging method or dataset, the BALI score varied significantly among different diagnoses (two-way ANOVA: $\mathrm{F}=32.03$, $\mathrm{p}<0.001$ ), with $\mathrm{AD}$ or MCI patients showing a higher BALI score than healthy controls $(\mathrm{p}=0.016)($ table 3$)$.
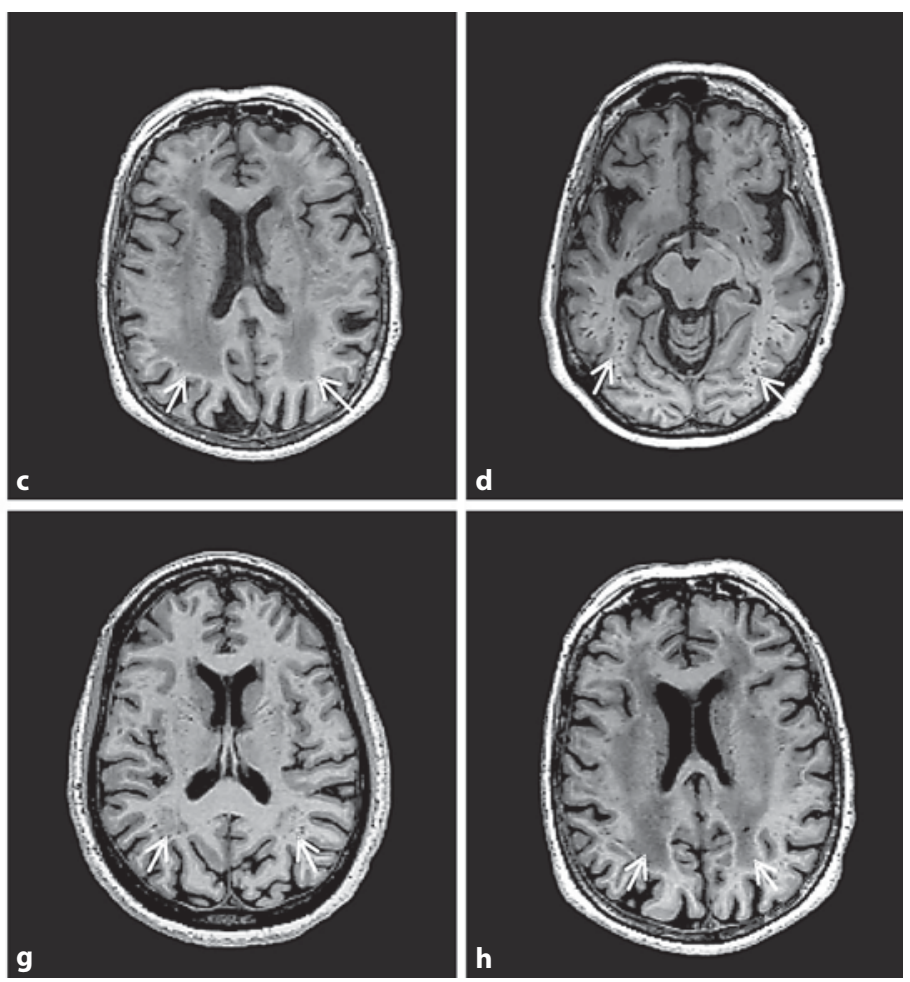

(b; IT = 3), periventricular areas $(\mathbf{c} ; \mathrm{PV}=3)$ and small vessels diffused in subcortical areas $(\mathbf{d} ; \mathrm{GM}-\mathrm{SV}=2)$. $\mathbf{e}-\mathbf{h}$ Lesions in DWM subcategory. Arrows: hypointensities. Corresponding lesion scores: 1 (e), 2 (f), 3 (g), 4 (h).

Despite the difference in mean values, T1WI- and T2WI-based BALI scores were highly correlated with a linear fit (fig. 2). Significant correlations between T1WIand T2WI-based scores were also observed for each diagnostic group in each dataset $(\mathrm{r}=0.87-0.93 ; \mathrm{p}<0.001)$. The T1WI-based subscores were also highly correlated with T2WI-based ones $(r=0.64-0.94 ; \mathrm{p}<0.001)$.

A lower BALI total score (i.e. less lesions), either T1WI or T2WI based, was associated with a higher cognitive test result (i.e. better performance; $r=0.21-0.29, p<0.05$ for T1WI-based score; $r=0.26-0.29, \mathrm{p}<0.01$ for T2WIbased score) (fig. 3a, b). Cognitive test scores were consistently related with brain atrophy, but not significantly related with brain lesions in most individual categories, except for BG in dataset 1 (fig. 3a, b).

Both the T1WI- and T2WI-based scores increased with age (fig. 3c, d). A strong correlation was observed for most lesion categories versus age. The slopes of the linear equation describing changes in T1WI- and T2WI-based BALI scores with age did not differ, although the intercept for the T2WI-based score was slightly higher (fig. 4).

Chen/Song/Zhang/Darvesh/Zhang/ D’Arcy/Black/Rockwood 
Fig. 2. Interrelations between T1WI- and T2WI-based BALI. Solid line: linear fit $\mathrm{y}=$ $\mathrm{a}+\mathrm{bx}$, where $\mathrm{a}=3.093, \mathrm{~b}=0.797, \mathrm{n}=249$, $\mathrm{r}=0.904$ (95\% CI: 0.879-0.925) and $\mathrm{p}<$ 0.001. Dotted diagonal line: T1WI-based scores $=\mathrm{T} 2 \mathrm{WI}$-based scores .

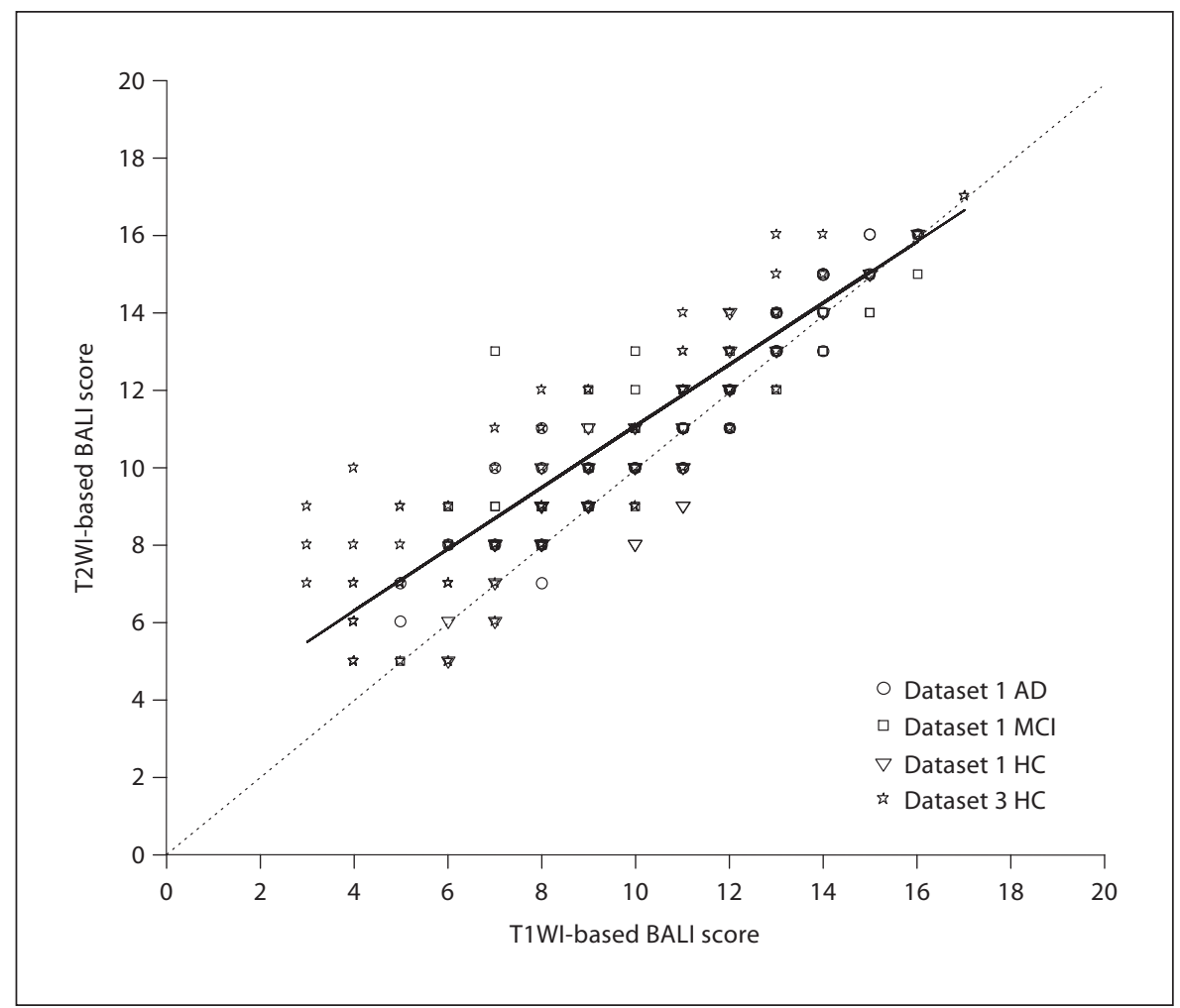

Table 3. Total and categorical scores of BALI

\begin{tabular}{|c|c|c|c|c|c|c|c|c|c|c|}
\hline & \multicolumn{10}{|l|}{ Dataset } \\
\hline & \multicolumn{6}{|l|}{1} & \multicolumn{2}{|l|}{2} & \multicolumn{2}{|l|}{3} \\
\hline & \multicolumn{2}{|l|}{$\begin{array}{l}\mathrm{AD} \\
(\mathrm{n}=35)\end{array}$} & \multicolumn{2}{|l|}{$\begin{array}{l}\text { MCI } \\
(n=68)\end{array}$} & \multicolumn{2}{|l|}{$\begin{array}{l}\mathrm{HC} \\
(\mathrm{n}=50)\end{array}$} & \multirow{2}{*}{$\begin{array}{l}\mathrm{AD} \\
(\mathrm{n}=14) \\
\mathrm{T} 1 \mathrm{WI}\end{array}$} & \multirow{2}{*}{$\begin{array}{l}\mathrm{HC} \\
(\mathrm{n}=30)\end{array}$} & \multicolumn{2}{|l|}{$\begin{array}{l}\mathrm{HC} \\
(\mathrm{n}=96)\end{array}$} \\
\hline & T1WI & T2WI & T1WI & T2WI & T1WI & T2WI & & & T1WI & T2WI \\
\hline \multicolumn{11}{|l|}{ Total score } \\
\hline Min, $\max$ & 5,16 & 6,16 & 5,16 & 5,16 & 6,15 & 5,15 & 6,16 & 6,15 & 3,17 & 5,17 \\
\hline Median & 11 & 11 & 11 & 11 & 10 & 10 & 11 & 9 & 9 & 9 \\
\hline Mean $\pm S D$ & $11.0 \pm 3.0$ & $11.5 \pm 2.8$ & $10.8 \pm 2.7$ & $11.3 \pm 2.3$ & $9.9 \pm 2.4$ & $10.0 \pm 2.4$ & $11.7 \pm 3.3$ & $9.6 \pm 2.6$ & $8.2 \pm 3.5$ & $9.6 \pm 3.1$ \\
\hline \multicolumn{11}{|l|}{ Category score } \\
\hline GM-SV (of 3) & $1.0 \pm 0.5$ & $0.9 \pm 0.5$ & $1.1 \pm 0.5$ & $1.1 \pm 0.5$ & $1.1 \pm 0.4$ & $1.1 \pm 0.4$ & $0.9 \pm 0.5$ & $0.8 \pm 0.6$ & $0.6 \pm 0.7$ & $0.7 \pm 0.7$ \\
\hline PV (of 3) & $1.9 \pm 0.8$ & $2.1 \pm 0.7$ & $1.8 \pm 0.8$ & $2.0 \pm 0.7$ & $1.6 \pm 0.7$ & $1.7 \pm 0.7$ & $2.1 \pm 0.7$ & $1.8 \pm 0.7$ & $1.9 \pm 0.8$ & $2.3 \pm 0.6$ \\
\hline DWM (of 5) & $2.1 \pm 1.1$ & $2.3 \pm 0.9$ & $2.1 \pm 1.0$ & $2.4 \pm 0.8$ & $1.9 \pm 0.8$ & $2.1 \pm 0.7$ & $1.9 \pm 1.2$ & $1.8 \pm 0.8$ & $1.7 \pm 1.2$ & $2.3 \pm 1.0$ \\
\hline BG (of 3) & $2.0 \pm 0.3$ & $2.1 \pm 0.4$ & $2.1 \pm 0.4$ & $2.0 \pm 0.4$ & $2.1 \pm 0.3$ & $2.1 \pm 0.5$ & $2.2 \pm 0.8$ & $2.0 \pm 0.7$ & $1.7 \pm 0.8$ & $1.8 \pm 0.8$ \\
\hline IT (of 3) & $2.1 \pm 0.7$ & $2.1 \pm 0.7$ & $1.9 \pm 0.5$ & $2.0 \pm 0.6$ & $2.1 \pm 0.5$ & $2.0 \pm 0.7$ & $1.9 \pm 0.6$ & $1.5 \pm 0.9$ & $0.7 \pm 0.9$ & $0.9 \pm 0.9$ \\
\hline GA (of 3) & $1.9 \pm 0.9$ & $1.9 \pm 0.9$ & $1.7 \pm 0.9$ & $1.7 \pm 0.9$ & $1.1 \pm 0.8$ & $1.1 \pm 0.8$ & $2.4 \pm 0.7$ & $1.6 \pm 0.8$ & $1.5 \pm 0.9$ & $1.5 \pm 0.9$ \\
\hline $\begin{array}{l}\text { Other lesions } \\
\text { (of } 3 \text { ) }\end{array}$ & $0.1 \pm 0.1$ & $0.1 \pm 0.1$ & $0.1 \pm 0.1$ & $0.1 \pm 0.1$ & 0 & 0 & $0.2 \pm 0.4$ & $0.0 \pm 0.2$ & $0 \pm 0.1$ & $0 \pm 0.1$ \\
\hline
\end{tabular}

Scores denote means \pm SD. HC $=$ Healthy controls. 

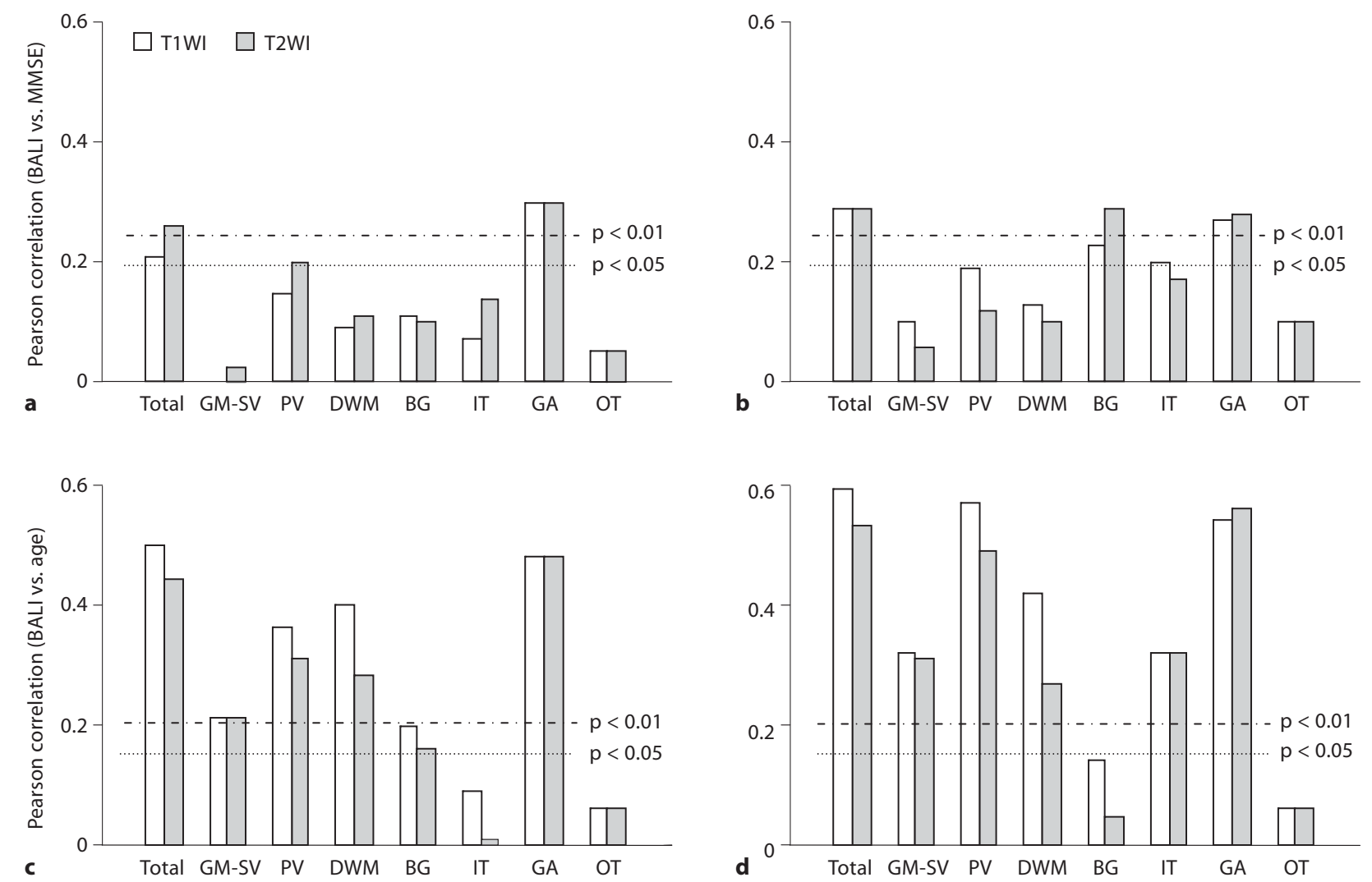

Fig. 3. BALI in relation to MMSE (a, b) and to age (c, $\mathbf{d})$ based on T1WI (white bars) and T2WI (gray bars) in datasets 1 (a, c) and 3 (b, d). Data presented are Pearson correlations for the total score and scores for various subcategories. Dotted lines: correlations reached the level of significance at $\mathrm{p}<0.05$. Dashed lines: correlations reached the level of significance at $\mathrm{p}<0.01$. a, $\mathbf{b}$ As the MMSE score was negatively correlated with the lesion scores, the correlations were multiplied by -1 .
When people of different diagnostic groups were considered separately, the significant correlation between age and the BALI scores still held. The BALI score was higher in men than in women $(10.0 \pm 3.4$ vs. $9.0 \pm 3.7 ; \mathrm{F}=$ $7.06 ; \mathrm{p}=0.009$ ).

T1WI- and T2WI-based BALI scores showed comparable accuracy at classifying people with $\mathrm{AD}$ at the individual level. At its midpoint (i.e. $\leq 10$ vs. $>10$ ), the BALI score sensitively predicted $17-20 \%$ more AD cases, with a sensitivity of $63-64 \%$, whereas it predicted $10-12 \%$ fewer healthy controls, with a specificity of $62-73 \%$ (table 4 ). The area under the curve (AUC) ranged between 0.67 and 0.70 (fig. 5).

\section{Discussion}

This is the first attempt to study the utility of a T1WIbased index of whole brain structural changes. Our data show that the BALI rating can be made on either T1WI or T2WI, thereby offering the possibility of evaluating brain anatomical changes even when T2WI and/or proton density imaging are not accessible. The data also support the hypothesis that the summed effect of lesions is more important than individual lesions considered in isolation. The BALI total score was more highly correlated with age and cognitive performance than were individual lesion scores. The BALI was also sensitive in detecting group differences in brain damage (i.e. the score 
Fig. 4. BALI as a function of age. Correlation between age and T1WI-based score (a), and T2WI-based score (b). Solid line: linear fit $(y=a+b x)$ for all subjects, regardless of dataset - for the T1WI-based score: $\mathrm{a}=-7.750, \mathrm{~b}=0.235, \mathrm{n}=293, \mathrm{r}=$ 0.535 (95\% CI: 0.482-0.643), p < 0.001; for the T2WI-based score: $\mathrm{a}=-3.884$, $\mathrm{b}=0.192, \mathrm{n}=249, \mathrm{r}=0.493$ (95\% CI: 0.393$0.582), \mathrm{p}<0.001$.

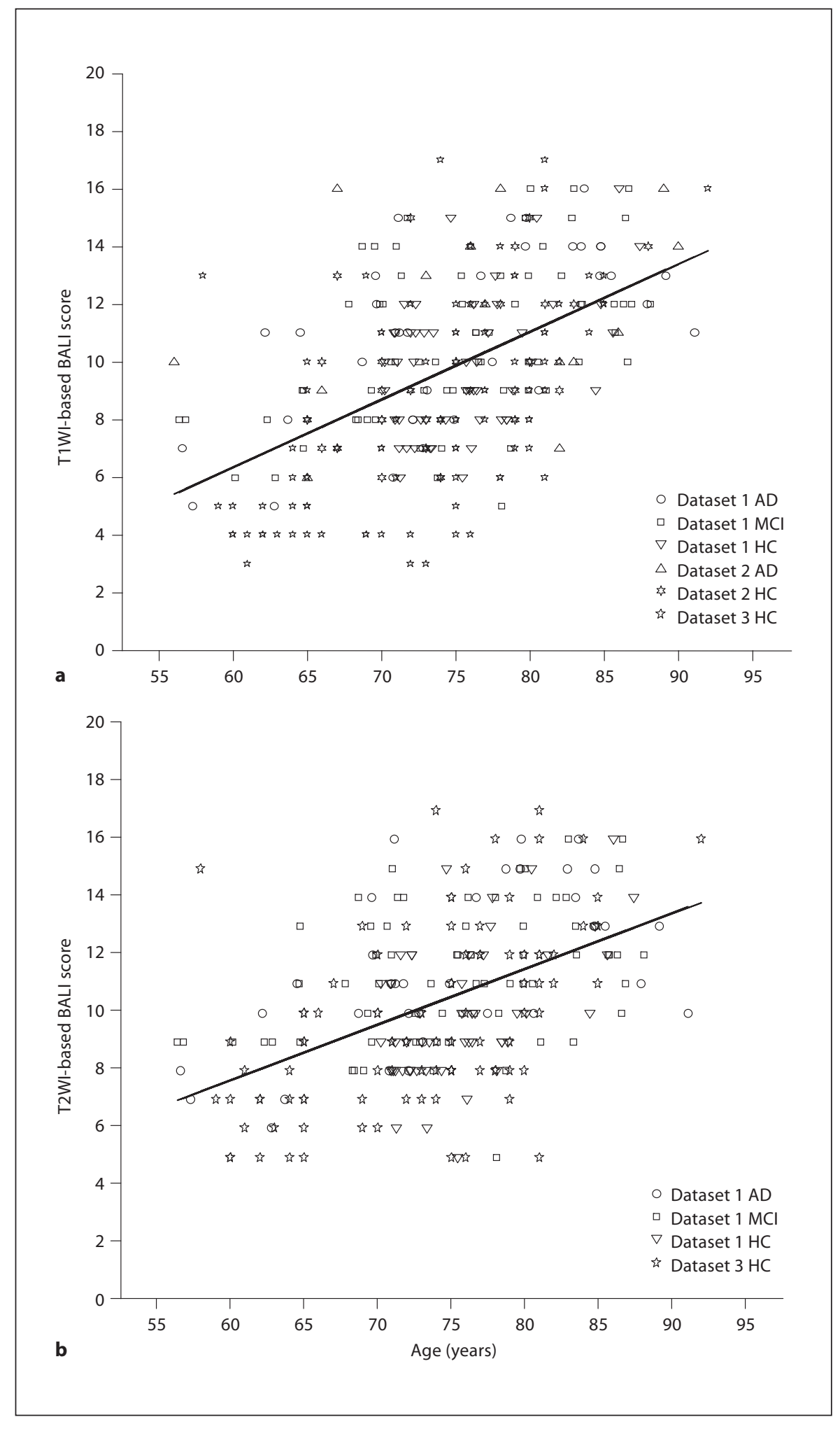




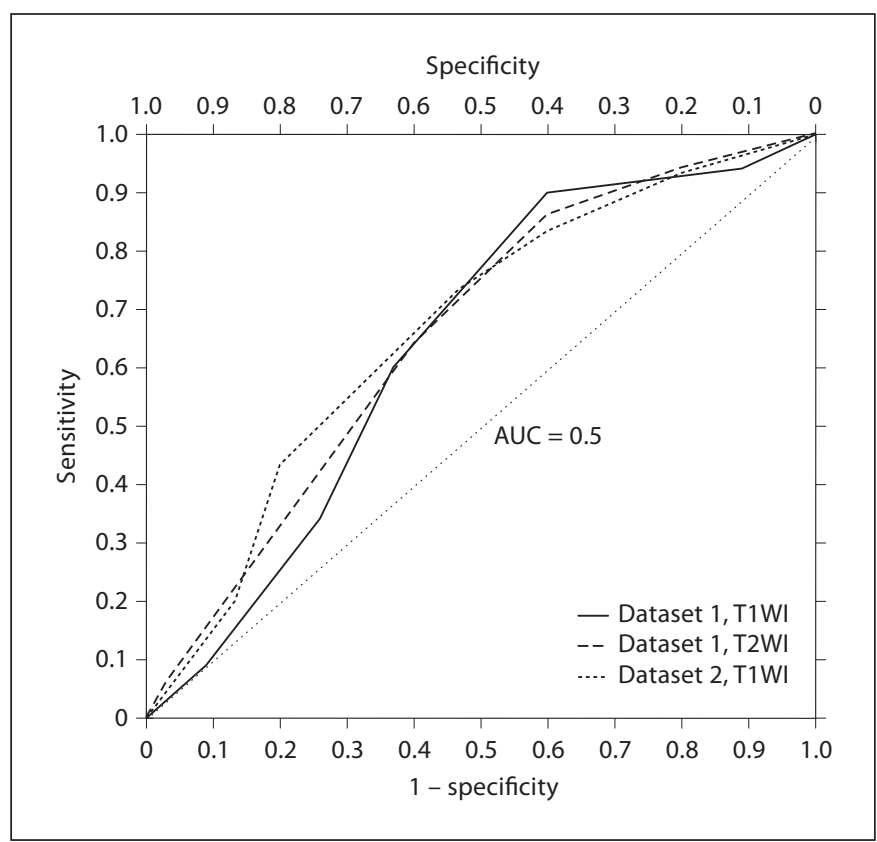

Fig. 5. ROC curves for identifying subjects with AD. Solid line: T1WI-based BALI in dataset 1 (AUC $=0.70 ; 95 \%$ CI: 0.57-0.83). Dashed line: T2WI-based BALI in dataset 1 (AUC $=0.67 ; 95 \% \mathrm{CI}$ : $0.56-0.79)$. Dotted line: T1WI-based BALI in dataset 2 (AUC $=$ 0.69 ; 95\% CI: 0.52-0.86).

was higher in MCI and AD patients than in healthy controls). This result is consistent with both clinical experience and the literature $[7,14,20]$. The BALI identified individuals with $\mathrm{AD}$ versus healthy controls moderately well. While preliminary, these results suggest that the BALI may provide an alternative method of identifying brain structural changes in AD. Generalizability of the BALI was tested using three independent datasets, with differences in participants, sample sizes and imaging acquisition methods. Although there were differences across various analyses, the main outcomes and the pattern of results were comparable.

Our findings must be interpreted with caution. As a visual rating scale, the BALI approach has the inherent lack of a more precise evaluation that requires quantitative measurements. As a quantitative analysis often involves time-consuming manual tracing and intensive expert input, in both research and clinical settings, a pragmatic scale can be quite favorable and useful. Further, the high interrater reliability indicates that different readers who have had satisfactory training in this method can rate the scans with some consistency.
Table 4. Accuracy of classification of BALI at its midpoint value (n)

\begin{tabular}{llrl}
\hline Predicted group & \multicolumn{2}{l}{$\begin{array}{l}\text { Actual group } \\
\text { [classification type] }\end{array}$} & Total \\
\cline { 2 - 3 } & control & AD & \\
\hline Control & & & \\
Data-1 - T1WI & $31(62)[\mathrm{TN}]$ & $13(37)[\mathrm{FN}]$ & $44(88)$ \\
Data-1 - T2WI & $31(62)[\mathrm{TN}]$ & $13(37)[\mathrm{FN}]$ & $44(88)$ \\
Data-2 - T1WI & $22(73)[\mathrm{TN}]$ & $5(36)[\mathrm{FN}]$ & $27(90)$ \\
AD & & & \\
Data-1 - T1WI & $19(38)[\mathrm{FP}]$ & $22(63)[\mathrm{TP}]$ & $41(117)$ \\
Data-1 - T2WI & $19(38)[\mathrm{FP}]$ & $22(63)[\mathrm{TP}]$ & $41(117)$ \\
Data-2 - T1WI & $8(27)[\mathrm{FP}]$ & $9(64)[\mathrm{TP}]$ & $17(121)$ \\
\hline Total & & & 85 \\
Data-1 - T1WI & 50 & 35 & 85 \\
Data-1 - T2WI & 50 & 35 & 44 \\
Data-2 - T1WI & 30 & 14 & \\
\hline
\end{tabular}

Values in parentheses denote percentages (actual group columns) or specificity and sensitivity (total column). Data-1/2=Dataset $1 / 2$; $\mathrm{TN}=$ true negative; $\mathrm{FN}=$ false negative; $\mathrm{TP}=$ true positive; $\mathrm{FP}=$ false positive.

While the T1WI- and T2WI-based BALI scores were highly correlated and showed similar relationships with age and cognition, they did demonstrate certain differences, especially in the PV and DWM categories. This finding is not surprising as subtle white matter damage may only appear as slightly increased T2WI signal intensities, and these might not be detected by T1WI. For this reason, evaluating subtle white matter lesions solely by T1WI may result in a lower score compared to using T2WI. Even so, the spatial resolution of T1WI in the ADNI dataset (and in most fMRI datasets) was higher than that of T2WI and sometimes revealed more detailed lesion features. Therefore, in a portion of the subjects, the T1WI-based scores were even higher than the T2WIbased ones. While a higher resolution of T1WI may serve as a tradeoff for a lower signal contrast, T2WI is more sensitive in detecting white matter lesions.

Currently, the BALI approach does not give special consideration to medial temporal lobe atrophy. It is known that such atrophy can serve as a sensitive marker for $\mathrm{AD}$, which may be used to distinguish normal aging from AD dementia [21-23]. Due to its high diagnostic sensitivity, especially when lateralization is taken into ac- 
count, medial temporal lobe atrophy is better evaluated using a more detailed scoring; one approach may even utilize morphovolumetric measuring of the substructures [22, 24-26]. It has been suggested that the rating of medial temporal atrophy can be applied in association with other important brain lesions [27, 28]. Previous research has shown that focal atrophy is highly correlated with diffuse atrophy in $\mathrm{AD}[24,29]$, so how this would add to the BALI is not yet clear.

Further research is needed (1) to investigate the utility of BALI in evaluating longitudinal changes of brain lesions, (2) to explore the possibility of weighting the items that make up the BALI, (3) to use the BALI with clinical assessments and neuropsychological tests for improved diagnosis and/or predictive accuracy, and (4) to help interpret brain functional changes. A better understanding of the relationship between lesion types, and the contributions of lesion volume and localization to their effect on function are especially of interest in future studies. For example, the small vessel disease has begun to draw significant research attention in recent years [2, 30,31], and while it has been included in the BALI construction, its particular link to lesion burden and/or atrophy warrants further investigation.

\section{Conclusion}

The semiquantitative BALI offers an alternative method of evaluating structural deficits in the $\mathrm{AD}$ and aging brain. The BALI showed consistent properties across different datasets in its content, construct and predictive validity. T1WI- and T2WI-based assessments were highly correlated, even though greater sensitivity of T2WI to white matter lesions resulted in higher values for that measure. The T1WI-based score can aid in understand- ing lesion burden for both functional studies and clinical evaluation, which makes T1WI-based brain lesion evaluation an interesting and potentially promising concept.

\section{Acknowledgments}

This research was supported by the Nova Scotia Research Foundation (grant No. NSHRF-MED2086) and the Capital Health Research Foundation (grant No. CDHA-RO33). W.C. receives an National Research Council fellowship from the Chinese Ministry of Education as a joint $\mathrm{PhD}$ candidate. K.R. receives career support from the Dalhousie Medical Research Foundation as the Kathryn Allen Weldon Professor of Alzheimer Research. We thank Alma Major, Janet Marshall, Careesa Liu and James Rioux for help with subject recruitment, screening and data acquisition; Steven Beyea, Chris Bowen and Robert Vandorpe for valuable discussion; Janet Marshall, George Flory and Elizabeth Vandermolen for proofreading of the manuscript.

Data collection and sharing for part of this project was funded by the National Basic Research Program of China (973 Program; grant No. 2010CB732500 and grant No. 30730036) and by the ADNI (National Institutes of Health Grant U01 AG024904). The ADNI is funded by the National Institute on Aging, the National Institute of Biomedical Imaging and Bioengineering, and via generous contributions from the following: Abbott, AstraZeneca AB, Bayer Schering Pharma AG, Bristol-Myers Squibb, Eisai Global Clinical Development, Elan Corporation, Genentech, GE Healthcare, GlaxoSmithKline, Innogenetics, Johnson \& Johnson, Eli Lilly and Co., Medpace Inc., Merck and Co. Inc., Novartis AG, Pfizer Inc., F. Hoffmann-La Roche, Schering-Plough, Synarc Inc. and Wyeth, as well as nonprofit partners (the Alzheimer's Association and Alzheimer's Drug Discovery Foundation), with participation of the FDA. Private-sector contributions to the ADNI are facilitated by the Foundation for the National Institutes of Health (www.fnih.org). The grantee organization is the Northern California Institute for Research and Education, and the study is coordinated by the Alzheimer's Disease Cooperative Study at the University of California, San Diego. ADNI data are disseminated by the Laboratory for Neuro Imaging at the University of California, Los Angeles. This research was also supported by NIH grants P30 AG010129 and K01 AG030514, and by the Dana Foundation.

\section{References}

$\checkmark 1$ Drayer BP: Imaging of the aging brain. Part 1. Normal findings. Radiology $1988 ; 166$ : 785-796.

2 Black S, Gao F, Bilbao J: Understanding white matter disease: imaging-pathological correlations in vascular cognitive impairment. Stroke 2009;40:S48-S52.

- 3 Schneider JA, Boyle PA, Arvanitakis Z, Bienias JL, Bennett DA: Subcortical infarcts, Alzheimer's disease pathology, and memory function in older persons. Ann Neurol 2007;62:59-66.
-4 Chen X, Wen W, Anstey KJ, Sachdev PS: Prevalence, incidence, and risk factors of lacunar infarcts in a community sample. Neurology 2009; 73:266-272.

5 Vernooij MW, Ikram MA, Tanghe HL, Vincent AJ, Hofman A, Krestin GP, Niessen WJ, Breteler MM, van der Lugt A: Incidental findings on brain MRI in the general population. N Engl J Med 2007;357:1821-1828.
6 Scheltens P, Erkinjuntti T, Leys D, Wahlund LO, Inzitari D, del Ser T, Pasquier F, Barkhof F, Mäntylä R, Bowler J, Wallin A, Ghika J, Fazekas F, Pantoni L: White matter changes on CT and MRI: an overview of visual rating scales. European Task Force on Age-Related White Matter Changes. Eur Neurol 1998;39: 80-89.

7 Fazekas F, Chawluk JB, Alavi A, Hurtig HI, Zimmerman RA: MRI signal abnormalities at $1.5 \mathrm{~T}$ in Alzheimer's dementia and normal aging. AJR Am J Roentgenol 1987;149:351356. 
8 Scheltens P, Barkhof F, Leys D, Pruvo JP, Nauta JJ, Vermersch P, Steinling M, Valk J: A semiquantitative rating scale for the assessment of signal hyperintensities on magnetic resonance imaging. J Neurol Sci 1993;114: 7-12.

-9 Wahlund LO, Barkhof F, Fazekas F, Bronge L, Augustin M, Sjögren M, Wallin A, Ader H, Leys D, Pantoni L, Pasquier F, Erkinjuntti T, Scheltens P: European Task Force on AgeRelated White Matter Changes: a new rating scale for age-related white matter changes applicable to MRI and CT. Stroke 2001;32: 1318-1322.

10 Bakshi R, Benedict RH, Bermel RA, Jacobs L: Regional brain atrophy is associated with physical disability in multiple sclerosis: semiquantitative magnetic resonance imaging and relationship to clinical findings. J Neuroimaging 2001;11:129-136.

11 Barkhof F, Scheltens P: Imaging of white matter lesions. Cerebrovasc Dis 2002; 13(suppl 2):21-30.

12 Desmond DW: Cognition and white matter lesions. Cerebrovasc Dis 2002;13(suppl 2):53-57.

13 van der Flier WM, van Straaten EC, Barkhof F, Verdelho A, Madureira S, Pantoni L, Inzitari D, Erkinjuntti T, Crisby M, Waldemar G, Schmidt R, Fazekas F, Scheltens P: Small vessel disease and general cognitive function in nondisabled elderly: the LADIS study. Stroke 2005;36:2116-2120.

-14 Rockwood K, Black SE, Song X, Hogan DB, Gauthier S, MacKnight C, Vandorpe R, Guzman A, Montgomery P, Kertesz A, Bouchard RW, Feldman H: Clinical and radiographic subtypes of vascular cognitive impairment in a clinic-based cohort study. J Neurol Sci 2006;240:7-14.

15 Heo JH, Lee ST, Kon Chu, Park HJ, Shim JY, Kim M: White matter hyperintensities and cognitive dysfunction in Alzheimer disease. J Geriatr Psychiatry Neurol 2009;22:207212.
16 Geerlings MI, Appelman AP, Vincken KL, Mali WP, van der Graaf Y, SMART Study Group: Association of white matter lesions and lacunar infarcts with executive functioning: the SMART-MR study. Am J Epidemiol 2009; 170:1147-1155.

17 Mueller SG, Weiner MW, Thal LJ, Petersen RC, Jack C, Jagust W, Trojanowski JQ, Toga AW, Beckett L: The Alzheimer's disease neuroimaging initiative. Neuroimaging Clin N Am 2005; 15:869-877.

18 Jack CR Jr, Bernstein MA, Fox NC, Thompson P, Alexander G, Harvey D, et al: The Alzheimer's Disease Neuroimaging Initiative (ADNI): MRI methods. J Magn Reson Imaging 2008;27:685-691.

19 Shrout PE, Fleiss JL: Intraclass correlations: uses in assessing rater reliability. Psychol Bull 1979;86:420-428.

-20 Holland CM, Smith EE, Csapo I, Gurol ME, Brylka DA, Killiany RJ, Blacker D, Albert MS, Guttmann CR, Greenberg SM: Spatial distribution of white matter hyperintensities in Alzheimer disease, cerebral amyloid angiopathy, and healthy aging. Stroke 2008;39: 1127-1133.

21 KesslakJP, Nalcioglu O, Cotman CW: Quantification of magnetic resonance scans for hippocampal and parahippocampal atrophy in Alzheimer's disease. Neurology 1991;41: 51-54.

22 Wahlund LO, Julin P, Johansson SE, Scheltens P: Visual rating and volumetry of the medial temporal lobe on magnetic resonance imaging in dementia: a comparative study. J Neurol Neurosurg Psychiatry 2000;69:630635.

23 Duara R, Loewenstein DA, Potter E, Appel J, Greig MT, Urs R, Shen Q, Raj A, Small B, Barker W, Schofield E, Wu Y, Potter H: Medial temporal lobe atrophy on MRI scans and the diagnosis of Alzheimer disease. Neurology 2008;71:1986-1992.

24 Jack CR Jr, Shiung MM, Gunter JL, O’Brien PC, Weigand SD, Knopman DS, Boeve BF, Ivnik RJ, Smith GE, Cha RH, Tangalos EG Petersen RC: Comparison of different MRI brain atrophy rate measures with clinical disease progression in AD. Neurology 2004; 62:591-600.
25 Saka E, Dogan EA, Topcuoglu MA, Senol U, Balkan S: Linear measures of temporal lobe atrophy on brain magnetic resonance imaging (MRI) but not visual rating of white matter changes can help discrimination of mild cognitive impairment (MCI) and Alzheimer's disease (AD). Arch Gerontol Geriatr 2007;44:141-151.

26 Devanand DP, Pradhaban G, Liu X, Khandji A, de Santi S, Segal S, Rusinek H, Pelton GH, Honig LS, Mayeux R, Stern Y, Tabert MH, de Leon MJ: Hippocampal and entorhinal atrophy in mild cognitive impairment: prediction of Alzheimer disease. Neurology 2007; 68:828-836.

$\checkmark 27$ de Leeuw FE, Korf E, Barkhof F, Scheltens P: White matter lesions are associated with progression of medial temporal lobe atrophy in Alzheimer disease. Stroke 2006;37:22482252.

28 Cho H, Kwon JH, Seo HJ: Medial temporal lobe atrophy in vascular dementia: visual temporal lobe rating scale. Arch Gerontol Geriatr 2009;48:415-418.

$>29$ Knoops AJ, van der Graaf Y, Appelman AP, Gerritsen L, Mali WP, Geerlings MI: Visual rating of the hippocampus in non-demented elders: does it measure hippocampal atrophy or other indices of brain atrophy? The SMART-MR study. Hippocampus 2009;19: 1115-1122.

30 Black S, Iadecola C: Vascular cognitive impairment - small vessels, big toll: introduction. Stroke 2009;40:S38-S39.

31 Richard E, Gouw AA, Scheltens P, van Gool WA: Vascular care in patients with Alzheimer disease with cerebrovascular lesions slows progression of white matter lesions on MRI: the Evaluation of Vascular Care in Alzheimer's Disease (EVA) study. Stroke 2010; 41:554-556. 